\title{
XXXII. On arithmetical complements
}

\section{Mr. Peter Nicholson}

To cite this article: Mr. Peter Nicholson (1818) XXXII. On arithmetical complements, Philosophical Magazine Series 1, 52:245, 210-212, DOI: 10.1080/14786441808652033

To link to this article: http://dx.doi.org/10.1080/14786441808652033

$$
\text { 曲 Published online: } 23 \text { Jul } 2009 .
$$

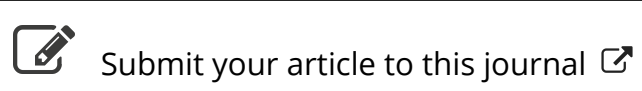

\footnotetext{
III Article views: 3
}

Q View related articles $\sqsubset$ 
bitants. At all events, it is, as far as I can learn, sooner or late destructive to Europeans in anywise affected with coughs, colds, or hæmorrhages from the lungs; and speedily so, to such as are at all predisposed to or affected with, tubercles or vomicæ. Various are the calamitous instances that could be adduced, both in the navy and army, of the rapid progress and fatal termination of this, even amid the prevalence of other disorders peculiar to the climate. I have had some cases of pneumonia; and have at present one of vomicæ, which originated in a voyage to Greenland about eighteen months ago, I have also in my mind at this moment the particular case of a captain of foot, who was cut off in the flower of his age, at Montreal, in the winter of 1815 , by this disease, aggravated as it strikingly was by the pernicious influence of the climate. Indeed, the peculiar susceptibility of the body to be acted upon by the relaxation or particular action of the exhalants, from a temperature so varying, is very great **********

XXXII. On Arillmetical Complements. By Mr. Peter Nicholson.

I uave been greatly surprised to find that the use of arithmetical complements has been entirely confined to logarithms, and that they are treated as if they only resulted from the properties of those artificial numbers. But whoever has much practice in finding the roots of equations by approximation, or in any other way, must have felt the confusion of so many changes of signs which require the negative and affirmative numbers to be added together separately, and then their differences to be taken: whereas, if we were to use not arithmetical complements, but numbers found in a similar manner, we need only add the whole together in one compact sum.

And thus it may be seen that arithmetical complements are a branch of common arithmetic, and not at all peculiar to, though very useful in, logarithms, nor their uses entirely confined to logarithrns, but are equally useful in arithmetic and algebra.

Let -31416 be a negative number : subtract each figure from 10 , and carry unity to the next figure; set the results in a row one after the other, proceeding from the right hand to the left, and prefix unity with a negative sign before the first figure. This simple operation may be done at sight, without putting the one number under the other, thus, $\overline{1} 68584$, where only the first figure is negative.

This number now found is not the arithmetical complement, but equivalent to the number itself : for $\overline{1} 68584=-100000$ $+68584=-31416$. 
The arithmetical complement of any number is what that number wants of another number, which has mity for the left hand figure followed by as many ciphers as are digits in the proposed number. This is equivalent to the usual definition; but in my opinion it is incorrect, and not congenial to any good principle of explaining this kind of practice. Authors usually direct to subtract every digit from 9 , except the last, which must be subtracted from 10 . But as to this, the reader may put in practice which method he thinks proper.

As my principal object is only to change such numbers as are put in opposition to affrmative numbers, and properly indicated by the sign - ; and in doing this I only find equivalent numbers, each composed of a negative and an affirmative part; this is therefore not a complement, it will thus be inconsistent to employ the term arithmetical complement; but as some term must be used in order to be understood, I shall therefore call the one number the reciprocal equivalent of the number proposed, as by the same operation the one may be converted to the other by observing the proper change of the signs,

I shall here present the reader with a few examples on this species of arithmetic.

\section{ADDITION.}

To add numbers which have different signs together.

$$
\text { Rule. }
$$

Find the reciprocal equivalents of the negative numbers: then add these equivalents and the affirmative numbers into one sum, and deduct the negative units that may be in any column from the sum of the column.

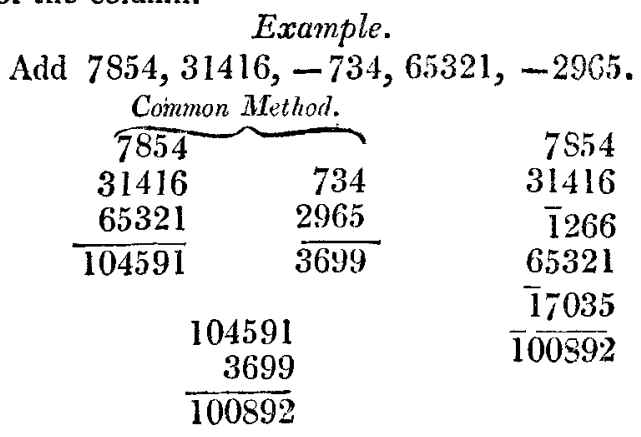

SUBTRACTION.

Add the reciprocal equivalent of the number to be taken away to the number which is required to be reduced, and the sum is the remainder.

Examples are unnecessary. 
MULTIPLICATION.

Supposing the multiplier an abstract number, multiply the affirmative part of the proposed number by the multiplier, and only set down as inany of the right figures as are in the number to be multiplied; then deduct the number formed by the remaining figures on the left from the product of the negative part. of the given number by the multiplier; prefix this difference with a negative sign over it before the affirmative part, and we have the product required.

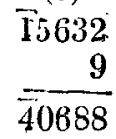

$$
\text { Examples. }
$$

9

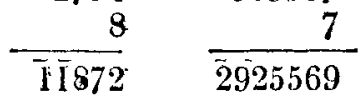

The reason is obvious, for $9 \times 15632=9 \times-10000+9 \times 5632$.

Now here any une of these products may be made to contain only a single negative unit in the first place of figures; by subtracting each of the negative digits from 10 , as in the preparatory rule.

Thus in the frist example the product $40688=\overline{1} 60688$ for: $160000=-100000+60000=-40000$.

$$
\text { Again, } \bar{l} \overline{1} 872=189872 ; \text { also } 2 \overline{9} 25569=\overline{1} 7125569 \text {. }
$$

DIVISION.

If the negative part is divisible by the divisor, write the quotient below, and place the negative sign over it: But if not divisible by the divisor, increase it till it becomes divisible; then whatever number was added to the negative part, in order to make it divisible, we must add an equal number to the affimative part and divide hy the divisor, and set down the quotient after the negative part.

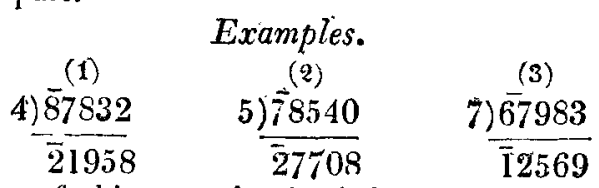

The reason of this operation is obvious, since the number to be divided consists of an affirmative and a negative part; therefore by increasing each equally, viz. the negative by a negative, and the affirmative by an affirmative, the difference is still the same. Thus in example second, the number to be divided is $78540=-70000+8540$; then if to the first of these last numbers we add -30000 ; and to the second we add 30000 , we shall have -100000 and 38540 , which are together equal to $\overline{78540}$. 